\title{
Fighting the Novel Coronavirus within the Context of Chinese Traditional Culture
}

\author{
Liming $\mathrm{Z}^{1 *}$, Jingyi $\mathrm{D}^{2}$ and Bowan $\mathrm{Z}^{3}$ \\ ${ }^{1}$ Xi'an Jiaotong University, China \\ ${ }^{2}$ Shanghai University, China \\ ${ }^{3}$ Hubei Academy of Fine Arts, China
}

*Corresponding author: Zhou Liming, Xi'an Jiaotong University, No-28, Xianning West Road,

Mini Review

Volume 3 Issue 3

Received Date: July 01, 2020

Published Date: July 21, 2020

DOI: $10.23880 /$ abca-16000125 Xi'an, Shaanxi, 710049, P.R. China, Tel: +86 15114982917; Email: zhouliming@xjtu.edu.cn

\section{Abstract}

As a great nation, Chinese Ethnic Peoples has survived hardships time and still bedevil. Whether in dangerous or difficult situation, the classical Chinese culture with the full of the wisdom and ability has to deal with risks aggressively. Traditional Chinese Medicine (TCM) is from Chinese culture, has proactive responded the various epidemics. In the face of this new coronavirus, the classic Chinese culture theory and classic discourse have shown endless vitality, guiding the people of the whole country to overcome the difficulties, and have made a significant contribution to subside the epidemic around the world.

Keywords: Chinese Culture; Traditional Chinese Medicine (TCM); Epidemic Traditional culture is the Soul of a Country and a Nation

\section{Introduction}

Chinese Ethnic Peoples has endured the vicissitudes and suffered many trials in the past 5,000years, and especially in this coronavirus time. While the consciousness of risk and the countermeasures within the context of the Chinese classical culture, has supported us to derive the spirit of anti-epidemic, to set the specific measures and improve the levels of disease management, and also to strengthen the psychological counseling of citizens, to care about the humanistic nature to the public.

\section{Chinese Traditional Culture Embodies TCM to Fight Coronavirus}

Traditional Chinese Medicine (TCM) origins in Chinese classical culture, included in I Ching and Huang Di's Canon of Internal Medicines. It represents a treasure of ancient science in China, and a key to initiate the door of the Chinese civilization. At present, it is not only an important gateway for the prevention and control of the epidemic, but it also becomes for an advantageous period for Chinese medicine, as well as It represents a great time to show the Chinese culture to the world.

Chinese classical culture provides the principles of traditional Chinese medicine to fight the epidemic. Su Wen, $\mathrm{Ci} \mathrm{Fa}$ Lun records that "keep healthy, do not be evil" [1], and in the chapter of Lin Shu, Bai Bing Shi Sheng indicates that "Because of the virtual evil wind, and its body shape, the two virtual phases, is the shape of the guest" [2]. Wuhan, located in the intersection of Yangtze River and Hanshui, has a subtropical monsoon climate. Depending on the theory of TCM, the novel coronavirus belongs to "pathogenic factors" [3], and the cause of the disease is "dampness" [4]. Prevention and treatment of this pandemic must focus on correcting and eliminating evil. TCM National Expert Group believes that New Coronary Pneumonia is a "dampness malaria" [5], and the disease shows lunar (or yin), so the treatment should be primarily directed at cold-evil and damp evil. 
TCM performed well in the prevention and control of epidemic situation. Since the new coronavirus epidemic happened in Hubei's, a total of 2,220 people come from TCM system have been participated to fight against the epidemic. Many practitioners have joined in the fight against SARS in 2003. From the early stage of the epidemic, TCM experts went to Wuhan to investigate the actual situation to diagnose and treat patients, and to formulate treatment plans. The participation of Chinese medicine in confirmed cases in Hubei is more than $75 \%$ and more than $90 \%$ in other regions. In addition, TCM team has also developed Chinese medicine prevention and treatment plan, has widely used more than ten kinds of Chinese patent medicines and prescription soup, and has distributed more than 110,000.

Chinese culture was involved in the whole process from treatment to rehabilitation. Su Wen, Si Qi Tiao Shen Da Lun demonstrates that "The saint was not cured someone who has suffered the disease, but preserved who didn't get ill, and the disease could be controlled before infected" [6], and Sun Simiao has divided doctors into upper, middle, and lower grades. The upper grade doctors treated "not ill", the middle grade doctors treated "sickness 欲病", and the lower grade doctors treated "ill." In order to make sure the prevention and control of the new coronavirus pneumonia epidemic, TCM advocates "treating someone who not sick firstly", and implements a series of effective measures such as "to supervise the project supervision, center of gravity, intervention in the early stage, and full participation." Once someone infected or diagnosed, it should be using Chinese medicine for the first time. During the course of treatment, TCM practitioners also practices with the patients on " $B a$ Duan Jin Message Exercise 24-Form Tai Chi Chuan". Which are full of the essence of Chinese culture, to strengthen the body and expel the disease. In the recovery period, TCM has flexibly used lung function rehabilitation training such as "Gas adjustment, gas collection, nourishing gas, practicing gas, endurance, sputum discharge", and special methods such as "Acupuncture, Cupping, Scraping, Diet, Psychotherapy" to help patients recovered.

The history of Chinese civilization also as a book that recorded Chinese culture against many disasters in the past, for instance, it had happened 321 epidemics in China from the West Han Dynasty to the present. Zhang Zhongjing wrote our country's first monograph on the treatment of infectious diseases, Treatise on Cold Damage and Miscellaneous Diseases, and Ge Hong created Zhou Hou Bei Ji Fang, has first proposed immunotherapy to the world, and Li Shizhen's Compendium of Materia Medical was called an Chinese medicine encyclopedia by Darwin. Chinese classical books have clear records of measles, malaria, diphtheria, smallpox, chickenpox and other infectious diseases and treatment methods. Despite the epidemic had occurred in the Qing
Dynasty, and the population of China in that time has raised a lot. It is inseparable from the contribution of Chinese medicine. Smallpox was once a natural enemy of mankind. As Chinese culture gave birth to human pox vaccination, it has vanished in the world. Although epidemics threaten human's life and health since the ancient time, Chinese culture has never been absent in the history of fighting disasters for thousands of years.

\section{Chinese Traditional Culture Responses the Novel Coronavirus}

Chinese culture is the root and soul of China, and the Chinese government and leaders have attached great importance to use the power of culture to promote a compelling spiritual immunity among the people.

Firstly, since the outbreak, China has demonstrated its determination and confidence to work together in the same boat and against the epidemic. "People in the same condition help each other" comes from Sun Tzu Jiu Di, China effectively forestalls the spread of the epidemic in the world at the very beginning [7]. However, an increasing number of new cases coming from the outside have exceeded the newly confirmed cases in China. No country can stay out of the epidemic, and it is a time to face the challenge and work together, especially in the era of globalization only by sharing the same boat with the power and responsibility that lead us to safeguard the beautiful homeland of mankind.

Secondly, the epidemic is easy to forbid at the very first beginning, and the authority tries to enhance the protection of the masses. Avoiding medical treatment for taboo may cause minor sickness to become serious illnesses. The disease develops from the epidermis to the disease until it cannot cure at all. "Isolation disease at the beginning is easy, but the last lifesaving is difficult", this sentence comes from Fan Hua's Hou Han Shu, Heng Rong Ding Hong Lie Zhuan [8]. It means that it is easy to suppress the bad signs of things in their budding state, and it will be difficult to cure them when they cause trouble. There are some similar concepts, for example, "All difficult things in the world are sure to arise from a previous state in which they were easy, and all great things from one in which they were small" [9]. The key to curbing the epidemic and winning the epidemic lies in the daily routines of the people, which require us "wearing masks, washing hands, and ventilating". Besides, if we "check each household, prevent and control by everyone Household investigation, everyone prevention and control", and we can effectively control the epidemic.

Thirdly, getting rid of the troubles of the people and to strengthen the ruling power. The prevention and control of the epidemic must regard the human community as the 
key concept by gathering them together, and achieving the purpose of relieving hardship. As well as $\mathrm{Su} C h e$ in the Northern Song Dynasty has mentioned that "get rid of the people's trouble, just as wiping off the scourge", has reminded us to remove the people's scourges like removing our own diseases $[10,11]$. If the feet getting cold, the heart will be broken, and if people get hurts and it would damage the country. Thus, the safety and suffering of the people directly relate to the prosperity and decline of the country. While the sooner the epidemic ends the sooner the people can be transferred into the devoted into economic construction. Governing the country is enduring and the people are the most important. In the face of this epidemic, administrative personnel need to perform their duties with due diligence. They must not be fearful and procrastinating, but be proactive.

The fourth is taking precautions in advance in case of unexpected, and to enhance the control of the epidemic. Controlling a major epidemic is a key and priority for human security and social stability "Take precautions in advance in case of unexpected" origins from Zhen Guan Zheng Yao [12], which means preventing accidents in advance. This is the basic principle of administering the country. Only by raising awareness of danger and preventing risks and challenges can we plan ahead and prevent danger. It is the basic responsibility of leading cadres to resolve major epidemic situations; it is of great guiding significance and practical value to strengthen the sense of crisis and improve the ability to resolve risks for leading cadres. Just like the poem of $D u$ Xunhe in the Tang Dynasty has said, "The reefs in the creek with the rushing waves are very dangerous, people always careful when passing by. On the contrary, the water flow slowly without reefs is often delivered bad news that some people are drowned" [13] In the face of the epidemic, we must combine medical and preventive measures, and always remain cautious and be keen on perceptiveness. Besides, it necessary to pay attention to the dynamics of the epidemic, seizing the time to fight against diseases, and guarding against death, guard against joint control, and strive for the final victory of the epidemic.

Last but not least, people who are good at restraining disease always cut off the source of the disease firstly. It is necessary to find out the root of the source and to enhance the scientific research abilities in the academic world. In Bai Juyi's Ce Lin puts forward: "People who eliminate disasters always check the source first; those who are good at conditioning diseases always cut off the source of the disease original." Science and technology are the most powerful weapons for major epidemics, and mankind cannot defeat major epidemics without scientific research [14]. Since the outbreak, public health experts from all over the world are active in participated in the battle. The research, clinical, prevention and control lines have cooperated with each other and achieved major scientific research results.

\section{Chinese Traditional Culture Stimulates the Anti-Epidemic Spirit}

Awareness of potential danger is the origins of antiepidemic spirit. "Junzi do not forget the potential dangers when they are settled, and they could not ignore the vanishment as they survived, as same as ruling the country" [15] comes from "The Book of Changes" This sentence tell us governance and leaders require constant peace of mind and danger, and a sense of urgency, otherwise they could easily fall into passiveness and even suffer disasters. Si Maqia's Records of the Grand Historian mentions that King Zhou Wen was imprisoned in Youli to play The Book of Changes, which is a classic book equivalent to the Western "Bible" [16]. It is also a book represents the earliest in the world A classic of Chinese culture embodying the awareness of an unexpected development.

Fuhuo dependencies are the principle of the antiepidemic spirit. Disaster the place of blessing leans and the institute dog days of $\mathrm{Fu} \mathrm{Xi}$ disaster [17] "Honey melons hang on bitter vines; sweet dates grow on thistles and thorns" [18], which illustrates the dialectical relationship between sinking and revival, disaster and happiness very major epidemic has a painful price, however, the more serious the epidemic, the more unified everyone's thinking can be, and the more quickly a high-level consensus can be reached on some major social issues.

The spirit of fighting the epidemic comes from the traditional Chinese culture, which led the preliminary victory, to applaud its contribution around the world. There is only one earth in the universe, and mankind has a home. History proves that Chinese culture has made an indelible contribution to human civilization, as well as the globalization has unprecedentedly deepened the interdependence and interconnectedness of all countries in the world. China has a responsibility to form the anti-epidemic spirit for major human epidemics, and provide an effective plan for actively constructing a community by sharing a same future.

\section{References}

1. Hao Yi (2011) Huang Di's Canon of Internal Medicines. Beijing: Zhonghua Book Company. In: Wen S, Lun CF (Eds.), "Keep healthy, do not be evil is impossible, pp: 195.

2. Shu L, Shi Sheng BB (2011) The Birth of All Diseases: Because of the virtual evil wind, and its body shape, the two virtual phases, is the shape of the guest, pp: 321. 
3. "Evil spirit" (In Chinese).

4. "Dampness" (In Chinese).

5. "Wet plague" (In Chinese).

6. Wen S, Da Lun SQTS (2018) "The saint was not cured someone who has suffered the disease, but preserved who didn't get ill, and the disease could be controlled before infected."

7. Maguang S, Jiu Di ST, Jiudi G (2007) In Song Dynasty, Comprehensive Mirror in Aid of Governance (Zi Zhi Tong Jian). Beijing: Zhonghua Book Company, pp: 548.

8. Hou Hanshu, Biography of Huan Rong Ding Hong. "Isolation disease at the beginning is easy, but the last lifesaving is difficult". (In Chinese).

9. Difficult things in the world must be made easy; great things in the world must be made detailed. (In Chinese).

10. Che S, Dynasty S, Zaozhuang A, Defu M (2009) Luan Cheng Ji. Shanghai: Shanghai Classics Publishing House get rid of the people's trouble, just as wiping off the scourge in Chinese", pp: 468.

11. "Be prepared" (In Chinese).
12. Jing W, Dynasty T (1978) Zhen Guan Zheng Yao. Shanghai: Shanghai Classics Publishing House, pp: 71.

13. "Jingxi Stone Dangers are careful, they do not hear overthrow at the end of the year". (In Chinese).

14. Juyi B, Dynasty T, Ruming D, Shimei N, Juyi's B (1999) Shanghai: Shanghai Classics Publishing House. In: Lin C (Eds.). "Good beneficiaries check their roots, good benefactors have no source”, pp: 857.

15. "Be safe without forgetting danger, save without forgetting death, govern without forgetting chaos". (In Chinese).

16. Xi Z, Dynasty S, Mingchun L (2009) Original Meaning of I Ching (Zhou Yi Ben Yi). Beijing: Zhonghua Book Company, pp: 251.

17. Bizhu W, Dynasty W, Yulie L, Jing Zhu LZDD (2011) Beijing: Zhonghua Book Company. In: Chinese "Blessedness lies on the blessing, the blessing lies on the blessing", pp: 156 .

18. Deqian S, Dynasty Q, Xuchu W (2018) Origin of Ancient Poems (Gu Shi Yuan). In: Chinese "Cantaloupe holds bitter stalks, beautiful jujube thorn". Beijing: Zhonghua Book Company, pp: 83. 